\title{
АКСЕЛЕРАТОРЫ И БИЗНЕС-ИНКУБАТОРЫ РОССИИ В ОБЛАСТИ НАНОТЕХНОЛОГИЙ: ОТ ОБРАЗОВАТЕЛЬНЫХ СТАРТАПОВ ДО ТЕХНОЛОГИЧЕСКИХ РЕШЕНИЙ
} ACCELERATORS AND BUSINESS-INCUBATORS OF RUSSIAN FEDERATION IN A FIELD OF NANOTECHNOLOGIES: FROM EDUCATION STARTUPS TO TECHNOLOGICAL SOLUTIONS

\begin{abstract}
В.С. Шарощенко', к.п.н., старший преподаватель, (ORCID: 0000-0002-2028-1116), А.А.Ураловв,3, директор Научнообразовательного центра "Кузница Технологий", (ORCID: 000-0003-3566-4117), А.А.Гущина, , статс-секретарь Ассоциации акселераторов и бизнес-инкубаторов России, (ORCID: 0000-0003-2749-7777) / spektrvl@mail.ru V.S.Sharoschenko', Cand. of Sc. (Pedagogical), Senior Lecturer, A.A.Uralov',3, Head of Scientific and Educational Centre "Kuznitsa Technologiv", A.A.Guschina2,3, State Secretary of the Association of Accelerators and Business Incubators of Russia
\end{abstract}

DOI: 10.22184/1993-8578.2019.12.5.294.302

Получено: 29.04.2019 г.

Благодаря развитию нанотехнологий мировая экономика находится на пороге новой технологической революции. Нанотехнологии сегодня - это база любых технологий. В статье рассматриваются акселераторы и бизнес-инкубаторы в области нанотехнологий в российских вузах. Приведены примеры только что созданных площадок, стартапов и уже внедренных технологических решений.

World economics is on the verge of the new technological revolution because of nanotechnologies development. Today, nanotechnologies are the base of any technologies. In this paper we describe accelerators and business-incubators working in nanotechnologies on the basis of Russian institutes and universities. Presented are the just created examples of organized platforms and start-ups and already implemented technological solutions.

\section{ВВЕДЕНИЕ}

Общепризнанно, что благодаря развитию нанотехнологий мировая экономика находится на пороге новой технологической революции, которая неминуемо затронет в ближайшие десятилетия практически все области деятельности человека - от медицины и машиностроения до энергетики и космических исследований.

В 2018 году продажи в секторе нанотехнологий составили 500 млрд долл. США.

Прогнозируемый объем продаж в этом году, учитывая продвижение технологий, составит около 750 млрд. Также эксперты ожидают, что к 2020 году рынок нанотехнологий перешагнет порог в 2 трл долл. [2, 3, 4, 11].

В последние годы наблюдается устойчивая тенденция роста объема НИОКР в области нанотехнологий, а также все более широкое применение нанотехнологий и нанопродукции 
в различных областях науки и техники. Расходы на НИОКР в области нанотехнологий в мире возрастают ежегодно минимум на 10-15\%. До недавнего времени практически весь мировой объем инвестиций в НИОКР в области нанотехнологии (90\%) был сконцентрирован в 14 странах: США, Японии, Великобритании, Австралии, Германии, Израиле, Индии, Китае, Канаде, Южной Корее, Франции, Финляндии, Сингапуре и Тайвани.

Tак, в частности, о наличии разработан ных долгосрочных программ НИОКР в области нанотехнологий было объявлено США (2000 г.), Японией (2001, апрель), Кореей (2001, июль), ЕС (2002, март), Германией (2002, май), Китаем (2002), и Тайванем (2002, сентябрь).

С момента принятия Россией в 2007 году нанотехнологической инициативы картина принципиально изменилась как в организации НИР и НИОКР, так и в области нанотехнологий, внедрении их результатов и поддержке наноиндустрии, а также в финансировании этих направлений и становлении наноиндустрии как национальной наносети России.

Так, если в среднем ежегодно в США выделяют порядка 1,5 млрд долл. государственных средств в год на развитие нанотехнологичных проектов (соразмерное финансирование, в ЕС - 1,2 млрд и Японии - 1,0 млрд долл. США), то только в рамках ГК "РОСНАНO" на четыре ближайших года на работы в сфере нанотехнологий и поддержку наноиндустрии выделены средства в размере 4 млрд долл. Кроме этого, еще миллиард долларов планируется потратить на оснащение современным оборудованием научных лабораторий и внедренческих коллективов [11].

В настоящее время Россия по большинству позиций в области нанотехнологий имеет близкие стартовые позиции с ведущими странами мира и уже самым активным образом включилась в процесс освоения новых технологий. Так, сегодня на российском рынке производится и реализуется продукция нанотехнологий в объеме до 4 млрд руб. в год $[3,4]$.

При этом только две страны в мире - Россия и США - ведут исследования и разработки по всем направлениям нанотехнологий, в этих работах в Российской Федерации участвуют более 500 научно-исследовательских институтов и организаций, объединяющих свыше 30 тыс. исследователей.

Формированию нанотехнологий способствует динамика развития отраслей высоких технологий, выбранных государством в качестве приоритетных. Нанотехнологии сегодня - это база любых технологий.

Для коммерциализации инноваций необходимы систематизированные действия государства по развитию всей цепочки - от создания новых технологий до их массового внедрения. Схема "наука - технология - деньги", как и реализация инновационного проекта, переход от одной стадии к другой, требует обязательной обратной связи между промежуточными результатами НИОКР и рынком, поскольку деньги дает только рынок, а реализовать научный результат или технологию можно только в том случае, если она способна повысить чье-то конкурентное преимущество, принести или увеличить прибыль.

В целом коммерциализация научно-технических разработок в области нанотехнологий предполагает:

- оформление и регистрацию результатов научно-технической деятельности объектов интеллектуальной собственности;

- правовую охрану, оценку и обоснование использования объектов интеллектуальной собственности;

- технологический аудит результатов научнотехнических разработок;

- маркетинг научно-технических разработок и технологий для продвижения их на рынке;

- реализацию инновационного проекта (продажа лицензии, создание малого инновационного предприятия) [1].

Таким образом, используя системный подход в реализации комплекса организационнотехнических и экономических мероприятий, критериев оценки отбора новшеств, а также зная барьеры, тормозящие развитие технологий, можно решить проблему коммерциализации научно-технических разработок в сфере нанотехнологий.

Распоряжением Правительства РФ от 7 июля 2011 года № 1192-р были определены характеристики производственных объектов, которые можно отнести к "нанопродукции". На основании этого документа Росстат построил работу по государственному статистическому учету нанопроизводства. Из данных Росстата следует, что на сегодняшний день в России работают 287 производителей нанопродукции, из них всего 47 - проектные компании "РОСНАНО". Большая часть - независимые производители. Три четверти всей нанопродукции составляют нефтепродукты. 
Человек обладает руками, глазами и интеллектом, что определяет его технологический успех. Но при переходе на микро- и наноуровень технологу нужны увеличители. "Руки здесь заменяет технологический инструмент, глаза - научно-аналитическое оборудование. Однако, подобно тому как сельское хозяйство не давало результатов, пока не было достаточного количества лошадиных сил на площадь пахотной земли, инновации не дадут результата, пока не получат свои "лошадиные силы" - как бы мы ни бились и ни тратили деньги на организационные вопросы. Поскольку нанотехнологии в гараже и на коленке не делаются, нужны специализированные площадки-акселераторы с инженерными системами обеспечения технологическими ресурсами" [9].

До сих пор нет достаточного количества высокотехнологичного создающего оборудования. Также отсутствует прозрачный механизм использования аналитического оборудования: оно есть в сети ЦКП, но де-факто недоступно. На стадии развития любого проекта, будь то строительство дома, открытие торговой сети или запуск инновационного производства, сначала идут отрицательные денежные потоки, вложения в бизнес, и уже потом начинается отдача. Конечно, всякий предприниматель хочет, чтобы выход на окупаемость произошел раньше, а затраты бюджета были меньше. При уменьшении бюджета проекта снижается IRR (internal rate of return) - основной показатель, который интересует инвестора. Из четырех фундаментальных ресурсов, которые есть в резерве у инновационного предпринимателя (ноу-хау, команда, деньги, инфраструктура - помещение и инженерные системы), решение четвертой задачи существенно помогло бы инвесторами решить и три остальные задачи.

По мнению заместителя генерального директора Научного парка МГу Василия Петреченко, основная проблема развития инновационной инфраструктуры заключается в нехватке кадров. По его словам, в МГУ сейчас работает около сотни частных компаний, 30 из них имеют "достаточно прорывные инновации", которые находятся на уровне продаж от 0,5 до 10 млн долл. в год. Но эти компании не растут в течение уже 10 лет. "На наш взгляд, - говорит Василий Петреченко, - этим инновациям нужна молодая кровь. Нужно уделять дополнительное внимание программам подготовки, в том числе молодым менеджерам, которые будут развивать инновационные проекты. Эффективно делать это - в виде бизнесинкубаторов с глобальным видением рынка". В Научном парке МГу ежегодно проводятся образовательные программы: "Формула БИО", "Формула IT", "Формула успеха". Из 10 компаний - победителей прошлогодних конкурсов, съездивших на стажировку в США - 9 вывели свой продукт на рынок, 6 - полностью его переработали, отказавшись от первоначальных идей, 6 - "подняли" инвестиции общим объемом 150 млн руб. и создали 100 рабочих мест [7].

Большая надежда в развитии и коммерциализации инновационных нанотехнологических разработок в России возлагается на бизнесинкубаторы и бизнес-акселераторы.

Бизнес-инкубатор - это организация, занимающаяся поддержкой проектов молодых предпринимателей на всех этапах развития: от разработки идеи до ее коммерциализации.

По российскому законодательству, бизнесинкубатор - это "организация, решающая задачи, ограниченные проблемами поддержки малых, вновь созданных предприятий и начинающи предпринимателей, которые хотят, но не имеют возможности начать свое дело, связанные с оказанием им помощи в создании жизнеспособных коммерчески выгодных продуктов и эффективных производств на базе их идей".

Бизнес-акселератор (англ. business accelerator, startup accelerator или seed accelerator, буквально, "ускоритель") - социальный институт поддержки стартапов. Понятие описывает как учреждения, так и организованные ими программы интенсивного развития компаний через менторство, обучение, финансовую и экспертную поддержку в обмен на долю в капитале компании.

Очень часто свои инкубаторы есть у государственных и муниципальных учреждений и крупных вузов, а также компаний различного профиля. Тут стоит вспомнить о Постановлении Правительства РФ № 219 ("О государственной поддержке развития инновационной инфраструктуры в федеральных образовательных учреждениях высшего профессионального образования"), по которому в нескольких десятках российских институтов были созданы бизнес-инкубаторы. Сами инкубаторы часто существуют за счет дотаций от "донора" - учреждения, при котором они созданы.

В России действует более 100 различных бизнес-инкубаторов и акселераторов, помогающих 


\section{Где расположены Акселераторы и Бизнес-инкубаторы}

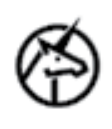

Акселераторы в субъектах РФ

\begin{tabular}{|l|l|}
\hline Москва & 6 \\
\hline Самарская область & 3 \\
\hline Санкт-Петербург & 2 \\
\hline Иркутская область & 2 \\
\hline Свердловская область & 2 \\
\hline Томская область & 1 \\
\hline Саратовская область & 1 \\
\hline Тамбовская область & 1 \\
\hline Курская область & 1 \\
\hline
\end{tabular}

19

Университетские акселераторы располагаются в 9 регионах из 85
Бизнес-инкубаторы в субъектах РФ

- 59 из 91 бизнес-инкубатора расположены в 17 сүбъектах $P \Phi$

- 91 инкубатор расположен в 49 субьектах РФ из 85

- 32 субъекта РФ имеют по 1 инкубатору

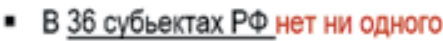
инкубатора

\begin{tabular}{|c|c|}
\hline Mocrisa & 15 \\
\hline Краснодарский мрай & 5 \\
\hline Томскея область & 5 \\
\hline Санк-Петербург & 4 \\
\hline Новосибирская область & 3 \\
\hline Пермсмий ирай & 3 \\
\hline Приморский мрай & 3 \\
\hline Хаберсеский мрай & 3 \\
\hline Воронежская область & 2 \\
\hline Ивановская область & 2 \\
\hline Кемеровская обпасть & 2 \\
\hline Новгородсквя область & 2 \\
\hline Республика Коми & 2 \\
\hline Республика Татарстан (Татарстан) & 2 \\
\hline Ростовская обпасть & 2 \\
\hline Саиарскяя область & 2 \\
\hline Удмуртская Республика & 2 \\
\hline
\end{tabular}

Ha 01.05.2018

Pис.1. Размещение акселераторов и бизнес-инкубаторов на территории России

Fig.1. Distribution of accelerators and business-incubators on the territory of Russian Federation

в развитии и реализации стартапов разного уровня.

Часть из них функционирует в составе ведущих вузов и федеральных университетов (рис.1). Среди них можно отметить акселераторы и бизнес-инкубаторы, помогающие продвигать на рынок новые технологические решения и инновации.

Акселератор МАИ при поддержке ФРИИ. Цель программы - акселерация студенческих ИТ-стартапов, связанных с высокотехнологичными проектами. Обучение на акселераторе помогает стартап-командам понять рынок, оценить свои силы, ознакомиться с современными методиками, найти механизмы повышения бизнес-показателей.

Трехмесячный трек предполагает самостоятельную работу команды проекта совместно с наставниками. В ходе работ команды смогут проверить гипотезы, преодолеть возникающие сложности, оценить потенциал проекта и определить направление, в котором двигаться дальше.

В рамках программы по ускоренному развитию ИТ-стартапов участники:
- работают над своими проектами с ведущими экспертами рынка;

- делают customer development и выявляют новые сегменты рынка;

- находят точки кратного роста продаж и узкие места в бизнесе;

- сводят unit-экономику в каналах;

- наращивают сеть полезных контактов.

Лучшие проекты представляют свои результаты перед инвесторами и потенциальными партнерами на финальном этапе (Демо день).

Бизнес-инкубатор НИу ВШэ. Основная акселерационная программа - HSE\{Pro\} - длится четыре месяца, набор участников проходит ежемесячно. Программа заканчивается Демо днем, где участники презентуют свой бизнес инвесторам и корпорациям.

Критерии отбора - наличие инновационной составляющей (в технологии или бизнесмодели) и способность к быстрому масштабированию. Отрасль может быть любой - образовательные технологии (edtech), медиа и маркетинг, большие данные и финтех, лайфстайлпроекты и b2b в сфере логистики. 
Также бизнес-инкубатор проводит отраслевые акселерационные программы в партнерстве с профильными компаниями. Среди них:

- PhilTech-акселератор - программа развития технологических проектов с социальным эффектом совместно с "Рыбаков Фондом";

- HSE $\{100 \mathrm{~K}\}$ - акселератор промышленных технологий при инвестиционной поддержке Phystech Ventures;

- HSE\{Pro\}Fintech - интенсивная программа развития проектов в области финансовых и блокчейн-технологий;

- HSE\{Pro\}Media - акселератор в партнерстве с медиахолдингом СМИ2, для стартапов в сфере медиа и рекламы.

Бизнес-инкубатор МФТИ Физтех "Старт". образовательная программа включает несколько направлений: поиск идеи и ее реализация, экономическая составляющая проекта, продвижение продукта, анализ рынка и потребителей, финансы и инвестиции.

Общий объем программы составляет 250 ч. Лекции проводятся представителями Microsoft, Intel Technologies, Planeta.ru, ФРИИ, ECommPay, UnaWheel, HudWay, ADigital, Global Venture, Alliance.

В активе Физтехстарт:

- менторская программа с участием успешных выпускников МФТИ, членов Физтех-Союза;

- выходы на резидентство в ведущие венчурные организации, такие как ФРИи, Сколково, Encata;

- помощь в инвестировании для лучших выпускников инкубатора;

- коворкинг для резидентов инкубатора в кампусе МФТИ;

- образовательная программа по созданию и продвижению продукта от ведущих предпринимателей и экспертов;

- трекерская программа от МФТи и ФРИи поможет с созданием индивидуального плана развития для каждого проекта.

Бизнес-инкубатор мГту им. Н.э.Баумана - объект университетской инфраструктуры поддержки проектных студенческих коллективов и отдельных предпринимателей. Инкубатор поддерживает их на ранней стадии деятельности, консультируя и предоставляя рабочие места в помещениях университета.

Бизнес-инкубатор занимается обучением и поддержкой менеджеров, способных действовать в изменяющихся ситуациях, так как основной причиной гибели инновационных компаний (до $70 \%$ ) является неадекватный менеджмент.

С 2008 года в Бизнес-инкубаторе Мгту им. Н.Э.Баумана создано более 60 успешных инновационных компаний.

Бизнес-инкубатор МГУ им. М.В.Ломоносова. Бизнес-инкубатор МГУ является подразделением Московского государственного университета им. М.В.Ломоносова и работает по принципу бизнес-акселератора. Это возможность для бизнес-проектов за четыре месяца довести идею до продукта без лишних ошибок, привлечь инвестиции и получить экспертную и менторскую поддержку.

Инкубатор предлагает:

- помощь в получении посевных инвестиций при получении статуса резидента;

- бесплатный коворкинг в Москве;

- контакты первых покупателей, клиентов, партнеров и потенциальных инвесторов;

- образовательную программу от внешних рыночных практиков;

- бесплатный пакет услуг от партнеров (ПО, хостинг, административная и юридическая поддержка);

- менторская и экспертная поддержка от топменеджеров ведущих компаний и серийных предпринимателей.

Инкубатор ищет идеи и проекты в сфере ИТ, направленные на решение существующей и актуальной проблемы.

Бизнес-инкубатор МПолитех. Бизнесинкубатор Московского политехнического университета создан для помощи молодым новаторам реализовывать и выводить на рынок их проекты.

Инкубатор работает по следующим направлениям:

- новые media технологии;

- creative-индустрия;

- инновации в образовании;

- Big Data, Quantum, Blockchain, Mobile apps;

- Augmented/Virtual/Mixed/Interactive Reality

- робототехника, Smart Robots;

- транспорт;

- Artificial Intelligence;

- Industrial;

- Agro Tech.

Акселератор технопарка "Русский" в Дальневосточном федеральном университете (ДВФУ).

Акселератор помогает резидентам продвигать или дорабатывать свои идеи для полноценной 
реализации на рынках. Предприниматели знакомятся с экспертами-трекерами и пробуют методы акселерации. Участники могут получить рабочее место в технопарке и встретятся с реальными инвесторами.

Технопарк "Русский" - проект дВФУ, Фонда "Сколково" и более 30 организаций в рамках утвержденной Правительством Российской Федерации Концепции развития острова Русский. Совместно с партнерами университет формирует экосистему для всесторонней поддержки технологических проектов и быстрого продвижения их на рынки Азиатско-Тихоокеанского региона. Сейчас в технопарке более 80 резидентов. В октябре 2018 года "Русский" был принят в международную Ассоциацию азиатских технопарков (Asian Science Parks Association).

Акселератор BiotechMed Generations в Томском государственном университете. Корпоративный акселератор, организаторами которого выступили РВК и Томский государственный университет.

BiotechMed Generations - один из ведущих российских акселераторов, который активно работает в сфере медицины, фармацевтики, нанотехнологий и биотехнологий.

Экспертами акселератора выступают представители PBK, Johnson\&Johnson, Martal Consulting Group, Sanofi, ГК "ЭФКО", компании ОМБ, KamaFlow, Биофармкластера "Северный", инновационного центра Российского олимпийского комитета и др.

Среди интересных и высокотехнологичных современных стартапов, поддержанных акселератором, являются:

"Экспресс-гемотесты ключевых биомаркеров мозга на раннее выявление острых и хронических поражений мозга ишемического и травматического генеза" (Анжей Жимбиев, г. Улан-Удэ). Для проведения экспресс-анализа на ишемический инсульт и сотрясение мозга необходима лишь капля капиллярной крови, результат регистрируется количественно с помощью специального приложения на смартфоне. Тестирование можно проводить в домашних условиях, при оказании неотложной помощи и в стационаре.

"Глазамер" (Александр Севастьянов, г. Новосибирск). Стереовизиометр позволяет с высокой точностью провести скрининговую диагностику тонких нарушений стереоскопического зрения, которые часто являются индикаторами других зрительных патологий.
"Создание ингибиторов альдостеронсинтазы" (Андрей Гилеп и Алексей Ключенович, г. Минск). Команда проекта разрабатывает новый класс лекарственных препаратов для лечения резистентной формы артериальной гипертензии, снижающих уровень альдостерона. Механизм действия разрабатываемых препаратов принципиально отличается от гипотензивных средств, существу ющих на рынке. Новый класс соединений способен снимать симптомы болезни в случаях, когда другие препараты оказываются неэффективными.

"Анатомичный УФ-хрусталик для глаза DAALe" (Андрей Гришин, г. Нижний Новгород). Уникальная методика с использованием отвердевающих под воздействием УФ-излучения линз решает множество проблем, возникающи при микрохирургическом лечении катаракты.

Среди российских акселераторов и бизнесинкубаторов, работающих в сфере инновационных технологических решений и нанотехнологий, можно отметить:

Акселератор HSE. Акселератор поддержки стартапов в сфере промышленной робототехники и "Индустрии 4.0."

При инвестиционной поддержке Phystech Ventures осуществляется акселерация программ для стартапов в сфере промышленных технологий ("Индустрии 4.0."). Акселерация имеет очно-заочный формат, проходит бесплатно и помогает участникам доработать продукт до инвестиций. Лучшие проекты получат инвестиционные предложения от 100 тыс. до 1 млн долл.

Среди приоритетных направлений - промышленная робототехника, индустриальный Интернет вещей и "умные" решения для инфраструктуры, системы автономного управления, компьютерное зрение, дроны, 3D-печать, сенсоры и электроника.

"Производственные технологии - сложная отрасль. Чтобы компании дойти до рынка, нужны деньги на доработку и внедрение продукта, пилотные проекты и продажи. Наша задача - помочь проекту выполнить текущие задачи, показать тенденцию и получить инвестиции, которые помогут реализовать продукт с глобальным потенциалом", - говорит Михаил Эрман, директор бизнес-инкубатора HSE [3].

Термин "Индустрия 4.0" емко объединил большинство фокусных направлений Phystech 


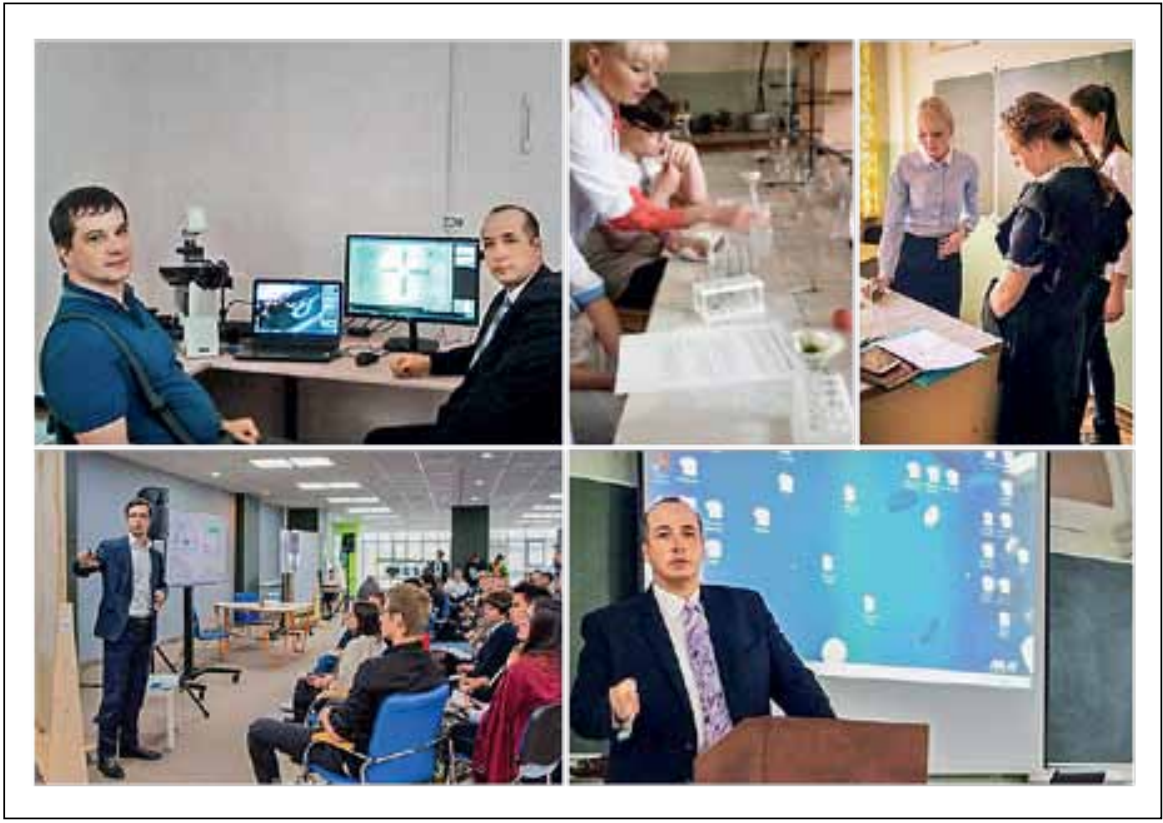

Рис. 2. Совместная работа преподавателей, студентов и школьников, направиенная на изучение и применение новых технологических решений в работе Дальневосточного федерального университета

Fig.2. Co-working of lecturers, students and pupils with the aim to study and apply new technological solutions in Far Eastern Federal University

Ventures: робототехнику, индустриальный Интернет вещей, сенсоры, аддитивные технологии и цифровизацию производства. Внедрение киберфизических систем, М2M и других новаторских технологий, растущая интеграция заводов приведут еще к большей оптимизации производства. Следующим этапом развития "Индустрии 4.0" станет ее выход за пределы заводов - в область подключенных автомобилей, умной логистики и умных городов. Мы надеемся увидеть интересные проекты, решающие задачи завтрашнего дня, и помочь командам в развитии бизнеса в России и на международных рын$\operatorname{kax}[3]$.

Акселератор "Т-НАНО" - нанотехнологический центр, специализирующийся в следующих перспективных отраслях:

- микроэлектроника;

- новые прорывные информационные технологии;

- аппаратные устройства;

- технологии хранения и передачи данных;

- робототехника;

- искусственный интеллект.

Основная задача - это создание и сопровождение технологических стартапов от запуска проекта до выхода из него. Миссия - создание эффективного механизма для серийного запуска, выращивания и продажи высокотехнологических бизнесов.

"Т-НАНО" финансирует инновационно-технологические стартапы, организует бизнес в инновационной сфере (принимая на себя роль предпринимателя), осуществляет частичное замещение проектных команд стартапов (в том числе выступая в роли управляющей компании), помогает стартапам найти партнеров и клиентов, запустить производство, выйти на рынок, найти дополни тельные инвестиции.

Выступая в роли инкубатора проектов, "Т-НАНО" запустил более 60 инновационно-технологических статапов. Соучредителями акселератора выступают : ОАО "Т-Платформы" - международный разработчик и производитель суперкомпьютеров и Фонд инфраструктурных и образовательных программ РОСНАНО.

Подчеркивая важность и значимость идей акселерации и учитывая тот факт, что большинство российских акселераторов и бизнесинкубаторов работает при ведущих российских вузах, необходимо учитывать тесную связь с образовательными технологиями и практиками, которые получили распространение в современном образовательном простран стве России. Среди держателей таких практик выступают: "Кружковое движение НТИ", Фонд "Сколково", сеть "Кванториум", сеть движения "Молодые профессионалы", проект "Точка кипения" и др.

Распространению практик наставничества и кружкового движения способствуют меры их поддержки Правительством РФ, региональными властями и университетами. В 2019 году планируется проведение более 18 региональных площадок, на которых будут обсуждаться достижения и перспективы развития практик наставничества в образовании, связь с промышленностью и реальным сектором экономики [3].

Крупнейшие региональные вузы могут стать ресурсными центрами реализации идей 
наставничества, пополняющих кадровый потенциал будущих стартапов, акселераторов и бизнес-инкубаторов.

Дальневосточный федеральный университет (ДВФу) являлся одним из российских вузов, которые активно используют практики наставничества и кружкового движения в реализации образовательных задач.

Ежегодно на базе ДВФУ проводятся различные мероприятия и площадки, на которых осуществляется совместная работа преподавателей, студентов и школьников, направленная на изучение и применение новых технологических решений и практик наставничества в работе вуза и школ региона (рис.2).

Среди многих мероприятий особый интерес представляют физико-математические и связанные с новыми технологиями:

1. Проект "точка кипения".

2. Чемпионат ДВФУ по стандартам "Молодые профессионалы" (WorldSkills Russia).

3. Проект "Лифт в будущее".

4. Центр проектной деятельности ДВФУ.

5. Технопарк "Русский".

Проявление талантливости, интереса студента к образованию можно стимулировать через приобщение его к научно-исследовательской деятельности. Это очень актуально, так как многие студенты вузов стремятся обеспечить себе высокий уровень образования и профессиональной подготовки.

Приобщение студентов к проектной и исследовательской работе позволяет им участвовать в образовательной среде, которая ориентирована на их интересы и потребности, дает возможность самовыражения, повышает их образовательный уровень, выявляет возможные недочеты и пробелы в полученных знаниях. Причем исследовательская и проектная работа должна вестись в контексте современного научного представления о материальности и дискретности мира. Подобные исследовательские проекты могут быть направлены, например, на эксперименты в наномире, позволяющие студентам лучше понять сущность нанотехнологий, объяснять их и вести исследовательскую работу в актуальных областях современной физической науки.

Такие исследовательские работы рекомендуется включать в вариативную часть обучения студентов при проведении спецкурсов по нанотехнологиям, современной физике и в курс "Основы проектной и исследовательской деятельности".

В Школе педагогики Дальневосточного федерального университета проводятся работы по спецкурсу "Нанотехнологии", предполагающие самостоятельное выполнение исследования, а также его анализ и защиту. Многое виды лабораторных работ не требуют глубоких познаний в той или иной сфере нанотехнологий или других специальных дисциплин, так как рассматриваемые явления достаточно хорошо проявляются на уровне микро- и макромира, и для их визуализации достаточно использовать оптический электронный и сканирующий атомно-силовой (или туннельный) микроскопы.

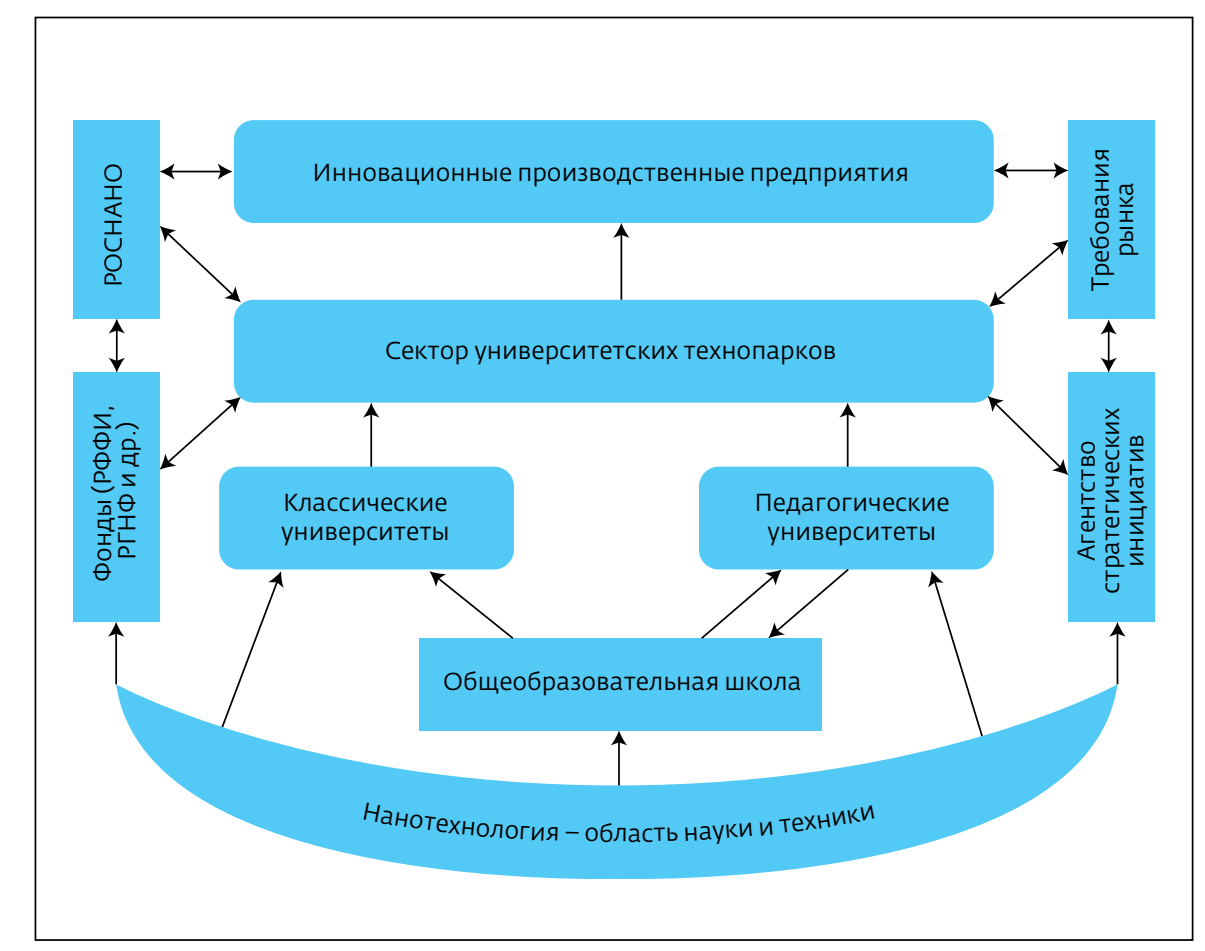

Рис.3. Включение инновационных образовательных направлений в процесс подготовки будущего специалиста (на примере нанотехнологий)

Fig.3. Innovative educational branches are included into preparing of a future specialist (on the example of nanotechnologies) 
Метод проектов, учебно-исследовательская и научно-исследовательская деятельность студентов имеют много общего, и использование любого способа проектирования обеспечивает достаточно серьезный научный уровень познания физических явлений и процессов.

Сфера нанотехнологий уже входит в нашу жизнь и будет все больше и больше укреплять свои позиции как одно из важнейших направлений развития науки и техники в 21 веке. Именно поэтому важной прерогативой развития общественных и государственных институтов является пристальное внимание всех государственных, общественных и образовательных структур к проблеме повышения качества и уровня знаний населения в области нанотехнологии.

Процесс обучения будущих специалистов основам нанотехнологий может стать ярким примером построения интеграционных связей во всех субъектах современного рыночного хозяйствования (рис.3). На основе ключевых технологий современности, образовательных программ школы и вузов осуществляется включение новых идей и технологий в такие структуры, как университетские технопарки, бизнесинкубаторы и акселераторы с соответствующим отбором и контролем со стороны госкорпораций, стратегических задач и требований рынка.

Дальнейшая разработка особенностей построения профессионально-ориентированной среды школы и вуза может способствовать формированию творческого мышления будущего специалиста, развитию инновационной проектно-исследовательской деятельности, отражающей новые формы объединения науки, техники и производства.

\section{ЛИТЕРATУPA / REFERENCE}

1. Antsiferova I.V., Esaulova I.A. nanotechnology research and education centers as an intellectual basis of nanotechnology in russia // Middle East Journal of Scientific Research. 2013. T. 13. № SPLISSUE. C. 127-131.

2. Examples of Programs and Courses on Nanoscale Science and Engineering Offered in U.S. Colleges and Universities. Электронный pecypc: http: // www.nano.gov/html

3. Электронный ресурс: http: // www.rusnano. com

4. Nanotechnology Update: U.S. Leads in Government Spending Amidst Increased
Spending Across Asia. Boston: LUX Research Inc. December 28, 2015. 21 p.

5. Баксанский О.Е., Гнатик Е.Н., Кучер Е.Н. Нанотехнологии, биомедицина, философия образования в зеркале междисциплинарного контекста. - М.: КД Либроком, 2010. 224 c.

6. Губина Н.В., Морзунова И.Б. Проблемы современной нанотехнологии. - М.: Дрофа, 2010. 270 с.

7. Гудилин Е.А., Третьяков Ю.Д. Фундаментальные подходы к развитию нанотехнологий, наноматериалов и подготовке кадров для наноиндустрии // Международный научный журнал "Альтернативная энергетика и экология". 2008. № 1 (57). С. 9-16.

8. Еремин В.В., Гудилин Е.А., Еремина Е.А., Третьяков Ю.Д Олимпиада "Нанотехнологии - прорыв в будущее" // Российский химический журнал. 2011. Т. 55. № 5-6. С. 77-84.

9. Ливанов Д. Образование должно быть адекватно наноиндустрии // Приложение к газете "Коммерсантъ" № 221(4038). 2008. 4 дек. Электронный ресурс: http: // chermet. info/index.php?option 35

10. Остапюк С.Ф. Инновационная парадигма развития наноиндустрии и проблемы ее реализации // Проблемы современной экономики. 2007. № 4 (24).

11. Раткин Л.С. Состояние и перспективы развития наноиндустрии в Российской Федерации // НАНОИНДУстРИЯ. 2018. № 7-8. С. 520-524.

12. Роко М. Перспективы развития нанотехнологии: национальные программы, проблемы образования // Российский химический журнал. 2012. T. XLVI. № 5. С. 90-95.

13. Третьяков Ю.Д. Проблема развития нанотехнологий в России и за рубежом // Вестник РАН. 2007. № 1.

14. Устинова Н.Г. О подготовке кадров для наноиндустрии // Вестник СГСЭУ. 2011. № 56. С. 64-68.

15. Шарощенко В.С. Проектная и исследовательская деятельность будущих учителей физики в области нанотехнологий // НАНОИНДУСТРИЯ. 2018. № 2. С. 53-56.

16. Шарощенко В.С. Подготовка будущего учителя в области нанотехнологии при обучении общей физике в педагогическом вузе: учебно-методическое пособие для преподавателей ВУЗов. - М.: Библиоглобус, 2018. 197 с. 


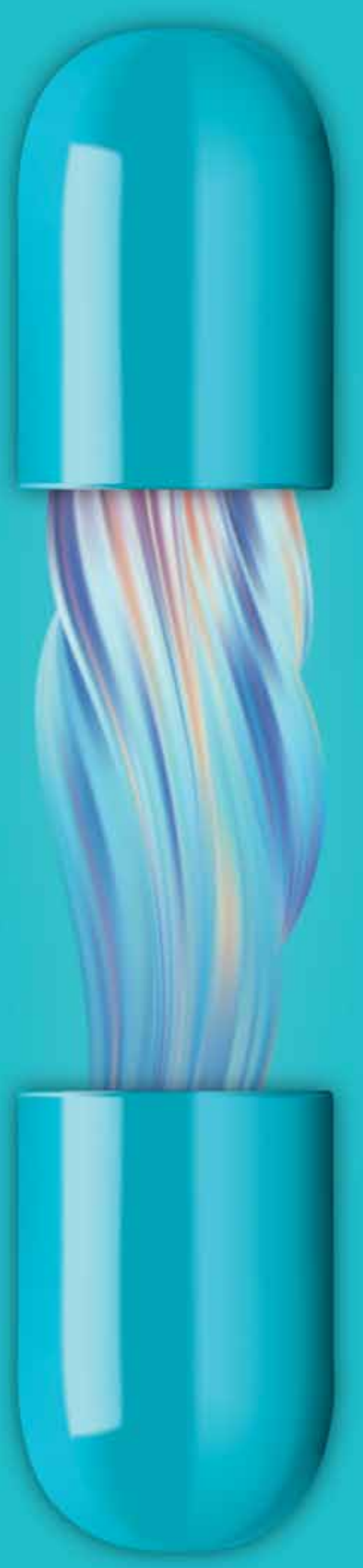

pharmtech

8 ingredients

Международная выставка

оборудования, сырья и технологий

для фармацевтического производства

$19-22.11 .2019$

Россия, Москва

МВЦ «Крокус Экспо»

\section{Получите}

\section{билет по \\ промокоду}

\section{pha19N}

pharmtech-expo.ru 